\title{
Mediation, translation and local ecologies: understanding the impact of policy levers on FE colleges
}

By Ken Spours*, Frank Coffield* and Maggie Gregson^^

* Institute of Education, University of London

$\wedge$ University of Sunderland

Corresponding author: Dr Ken Spours, School of Lifelong

Education and International Development, Institute of Education, University of London, 20 Bedford Way, London, WC1H OAL.

k.spours@ioe.ac.uk

Submitted for special issue of JVET for ESRC

TLRP project: The impact of policy on learning

and inclusion in the learning and skills sector. 


\section{ABSTRACT}

This article reports the views of managers and tutors on the role of policy 'levers' on teaching, learning, and inclusion in colleges of Further Education (FE) in our research project, 'The impact of policy on learning and inclusion in the Learning and Skills Sector (LSS)'. ' Using data from five research visits conducted over two years in eight FE learning sites, we explore the processes by which colleges 'mediate' and 'translate' national policy levers and how this affects their ability to respond to local need. The paper tentatively develops three related concepts/metaphors to explain the complexity of the policy/college interface - 'the process of mediation', 'acts of translation' and 'local ecologies'. We found that policy levers interacted with a complex set of national, local and institutional factors as colleges responded to pressures from the external environment and turned these into internal plans, systems and practices. We conclude by suggesting that national policy-makers, who design national policy levers, may not be fully aware of these complexities and we make the case for the benefits of greater local control over policy levers, where these interactions are better understood. 


\section{AIMS}

Further Education colleges (FE) offer a particular insight into the workings of the Learning and Skills Sector (LSS) and how policy levers impact on learning and inclusion. An historical perspective enables a comparison of the impact of the policy and regulatory regimes of the Further Education Funding Council (FEFC) $)^{i i i}$ and, now, the Learning and Skills Council (LSC). Furthermore, the size and diversity of these institutions also present analytical challenges and opportunities. We are able to observe how the eight learning sites within four colleges, have responded to the demands of the external environment (e.g. national policy, the regulatory regimes of the LSC and local contexts) and how, as large institutions, they 'translate' these external demands into institutional plans. We can also see how within the institution, policy levers interact with a range of other factors - national, local and institutional and go through a complex 'mediation' process to produce cultures, systems and practices that affect learning and inclusion.

This paper draws upon research data from 74 interviews with tutors and managers, undertaken during five visits between 2004-2006 to each of eight sites of learning in four FE colleges, two in London and two in the North East. ${ }^{\text {iv }}$ The managers were mainly from college departments or sections, responsible for the eight Level 1 and 2 courses that constituted these learning sites. However, we were able to interview principals or vice principals from each of the colleges who provided insights as to how large institutions position themselves in relation to the contexts of national pressures and local environments. For a fuller account of the research approach and the context of the sector, see the introductory paper in this collection (Edward and Coffield, 2007). While we have focused on a very small sample of the total number of FE colleges in England, we felt it necessary to tease out the intricate ways in which colleges both 'mediate' and 'translate' national policy. ${ }^{\vee}$ 
Like others (e.g. James and Biesta, 2007), we refer to 'mediation' as a general process by which a range of actors interact with policy. In this paper we focus, in particular, on actors at the level of the FE college. From a system and policy-making perspective, we also use the term 'policy mediation' to look at what happens to policy as it travels through the different levels of the LSS and through different stages of the policy process. Translation is used to refer to specific interpretative acts by either professionals or policy-makers within the general process of mediation. These terms are elaborated further in Section 4.

\section{CHALLENGES FROM NATIONAL POLICY AND LOCAL ECOLOGIES}

An analysis of events in the 13 years since the Incorporation of FE colleges reveals both continuity and change and the continuities are as significant as the changes. Despite major growth and efficiency gains, colleges still cater for a diverse range of learners including the most disadvantaged (Stanton 2004). FE colleges continue to compete in local education and training markets and are constantly required to respond to pressures for change (Perry and Simpson 2006). Even though the achievements of FE are very important to the life chances of younger and adult learners, FE tutors still find their terms and conditions of employment noticeably less favourable than their counterparts in schools.

What has changed since 2001 is that FE colleges in England have moved from being exclusive members of a discrete national college sector to becoming part of an expanded LSS. Whilst they, like other major players, broadly accepted the idea of a unified LSS (Hodgson et al., 2005), some senior managers in our study complained that, unlike the FEFC, the LSC did not really understand colleges or how they 
operated. They also felt that LSC policy was highly directive yet, at the same time, unstable. Colleges reported that they had to cope with instabilities resulting from changes in national priorities, targets and funding, while at the same time, responding to a repertoire of other policy levers, such as inspection and a range of initiatives, all accompanied by their own paper-based accountability regimes (Steer et al., 2007).

As well as shifts in policy, colleges also face different 'local ecologies'. We use this term as a way of conceptualizing the dynamic of relations within a locality. Among its potential uses, discussed further in Part 4, the concept of local ecologies helps to explain important differences among the environments in which the four colleges in our study function. For instance, Beechtree College ${ }^{v i}$ is a rapidly expanding city-based college with a broad potential market, while Alder College is more constrained in an economically deprived area of high unemployment. District College has a strong community base that fundamentally shapes its response, while Central College is dependent on encouraging different groups of learners to make a long and often complex journey to learn in a highly competitive environment. It also caters for a large number of refugees. Furthermore, the four colleges operate within different economic environments within two very contrasting regions - the North East and London - which affect cultural and social attitudes and economic opportunities. In attempting to meet the needs of learners, communities and employers, colleges have to negotiate the challenges of national policy, translate policy levers and, at the same time, respond to local ecologies. 


\section{THE EFFECTS OF POLICY LEVERS AND OTHER FACTORS ON LEARNING ${ }^{\text {vii }}$}

\section{The five policy levers}

During the site visits, middle managers and tutors were asked about the role of five policy levers in their institution. We use the term 'policy levers' to refer to instruments of governance chosen by government to regulate institutional performance. In the case of this project, we have focused on the role of planning, targets, funding, inspection and policy initiatives (for further discussion of the concept of policy levers, see Steer et al., 2007). During the interviews practitioners were also asked to list all the factors they thought had a major influence on learning and inclusion. We have broadly grouped these into 'policy levers' and 'other factors'. These two sets of influences are highlighted in Figure 1 and then discussed.

Figure 1. Factors influencing TLA and inclusion in eight FE sites: responses of interviewees

(Insert Fig 1 about here)

\section{a. Planning - national and institutional}

The LSC approach to planning appears has changed, being now more focused on steering institutions towards government priorities than on promoting area-based coordination (Steer et al. 2007). Three out of the four principals interviewed thought that their colleges were increasingly 'strait-jacketed' within the LSS, due to lack of funding stability, erratic and bureaucratic relationships with the local LSC, tensions within national policy and the highly directive nature of targets. 
An overarching issue was funding instability within the sector and the inability of the LSC to deliver an environment in which the college could plan ahead. One principal stated: 'We keep being promised the stability of three-year plans, but we never get there because the plans have to be re-written every year (ZA12), while another remarked: 'Our three-year plan has been suspended...so I can't tell you what will happen to the college next year' (ZA06).

A second theme was the perceived lack of local LSC capacity to have a dialogue with college managers, one of whom asserted: 'you couldn't have a sensible and technical conversation with somebody at the local level about a funding issue because there were just people without the skills there' (ZA13). Another referred to the local variability of relationships with the LSC: 'Colleges thrive or don't thrive depending on the environment created at the local level by the [LSC] regional director and then the people at regional or sub-regional level' (ZA06). Other comments referred to what we have termed 'policy tension' (Hodgson et al. 2005). One senior manager (ZA13) commented on the influence of 'broad objectives... above the targets' that, he maintained, lacked coherence. In particular, reference was made to the tensions within DfES policy, for example, simultaneously promoting both competition and collaboration.

\section{b. Targets and funding}

Within the LSS, targets, funding (and inspection) have become closely related policy levers because extra funding for colleges is dependent on achieving performance indictors in relation to learner numbers, employer engagement, learner success rates and professional qualifications for teachers, lecturers and trainers (LSC, 2003). However, the precise ways in which targets and funding interacted in the four colleges and the eight learning sites, suggest a complex set of enabling and 
hindering influences.

The combined effect of targets and funding can disrupt a college's engagement with its local ecology. For instance, senior managers argued that shifting national priorities and targets not only inhibit medium-term planning, but can deflect a college from meeting the needs of disadvantaged learners (ZA05) or from being flexible and innovative in the deployment of its resources (ZA13). However, within colleges, targets were not always seen as a negative influence by staff and wider research within the LSS suggests that FE managers recognize their strategic role (Perry and Simpson 2006). One middle manager appreciated their focusing effect: 'Targets focus the mind a lot...you have an eye on them and the team discusses them and so do I, endlessly' (B2M3/3). Another talked about 'putting figures up and making sure that everyone achieves and that you provide support to enable them to achieve' (C1M1/2). It is possible to reconcile these different views by making a distinction between the imposition of top-down targets and a more collegial discussion of institutional or departmental aims to support learners.

These positive reflections on the role of targets, however, were offset by criticisms; for example, the way that targets have been defined can undermine the role of FE in helping young people make the move from a full-time college course to a work-based apprenticeship route:

'We say our FE is the creche for work-based learning really ... we get penalised. The LSC say "Work-based learning is looking good but FE looks terrible". They never realise ...It is the same person, and you see, I actually believe that that is progression and success, but it isn't for the LSC' (A2M1/2).

A much broader criticism concerned the transaction costs of accountability. 
Paperwork multiplied as staff had to cope with the bureaucratic demands of meeting the targets as well as those for funding and inspection. Their combined effect diverted attention away from teaching and learning and added to the workloads of staff. Senior experienced tutors were working long hours in the evening and weekends preparing lessons, marking scripts and catching up on administrative tasks. Colleges can, however, make decisions as to how much paperwork and how much data tracking has to take place at different levels of the institution. Some appeared to make more of it than others. One manager, with experience of several colleges, commented on all the data he received, most of it generated by tutors:

'I've never seen a college like it in terms of the amount of data I get every week to evaluate. For example, because we've got electronic registers so we get electronic register reports every week' (D2M2/4).

Funding, linked to targets or not, remained a fundamental shaping influence on college behaviour. There were echoes of the FEFC era with middle managers continuing to see students as sources of funding. 'Students are money...will this student generate revenue?' (D2M1/2). However, the linking of student numbers, funding and targets could work against learner interests. We were told of examples of learners being directed towards low recruitment courses such as business studies, having applied for more 'strongly vocational courses' (Stanton 2004) such as construction, which were in greater demand. Learners who end up on courses to which they have little commitment or are unsuited are most at risk of dropping out (Martinez and Munday 1998); and if they become disruptive, such students become a burden to tutors. Middle managers and tutors were faced with contradictory messages from LSC guidelines regarding learner retention. As one remarked: 
achieve, it goes against you ... and sometimes keeping them has a detrimental affect on themselves and on the use of the scarce resource ... in that they may be disruptive and may take up an awful amount of various people's time' (C2M2/1).

If managers and tutors sometimes disagreed about the impact of funding and targets on courses and on learners, everyone was in firm agreement about the relative funding disadvantages of FE. College staff continue to be paid less than those in schools with one tutor remarking: 'the low level of funding in FE is hindering students' learning and achievement because it's preventing colleges from advertising and employing people with the required skills' (B2T2/1). By the time of our final research visit, cuts in adult funding were beginning to bite, courses were being closed and staff dismissed, contributing to a climate of uncertainty.

\section{c. Inspection}

Of the five policy levers, inspection was viewed most positively because it galvanised staff to focus on teaching and learning: 'the inspectorate has forced the drive in colleges because it is heavily biased on good teaching and learning' (A2M1/2) and provided a framework for improvement (D2M2/5).

On the other hand, the 'light touch' approach promised in policy texts was not recognised on the ground. One manager remarked on the potential threat from inspection based on the combined role of Ofsted ${ }^{\text {viii }}$ and LSC:

'It's fear of failure from the Ofsted inspections and the LSC. I mean the LSC has got quite a strong remit if it wishes to ... it can shut down whole departments. It can shut down whole colleges if it really wishes. Not that it 
would, it would be a nightmare' (C2M1/2).

Although inspections are now called at relatively short notice, middle managers and tutors still associate them with stress. Comments such as inspection, inspection, inspection' (C1M2/1) and having to cope with 'the horrendous bits of admin' and 'massive, massive workload' (D1T1/2) were made as colleges put in systems and practices to meet Ofsted criteria.

\section{d. Initiatives e.g. Educational Maintenance Allowances (EMAs) ${ }^{i x}$}

The most significant policy initiative in our study of FE was EMAs. EMAs were more prevalent in the two North East colleges than those in London because the latter catered for significant numbers of learners not eligible for them (e.g. older learners and refugees). Learners in receipt of an EMA appreciated it as a means of contributing to bus fares and learning materials, although staff suspected that, in some cases, because of family poverty the money went into family budgets, as evidenced by a sharp reaction from some parents if the allowance was suspended. Tutor and manager descriptions of the EMA and its effects on learner participation can be seen as potentially contradictory. On the one hand, EMAs were seen as a useful tool: EMA 'has helped with retention this year' (A1M1/1); and 'gives them another incentive to come to college' (A2TI/3); EMAs have caused 'a massive turnaround in terms of student attendance' (B2M1/1). On the other, they were also seen to encourage reluctant participation: 'I think the downside is if ... the only motivation to come to college is to receive the EMA money... that can be quite disruptive' (A1T1/3) and 'at times I wonder why some of these students are here' (D1T1/2).

\section{Other factors affecting learning}




\section{e. Needs of learners}

Social disadvantage, learner needs and learner behaviour were frequent themes during the interviews. In Hodgson et al. (2007) we reported that, out of 48 learners we interviewed on the first three site visits, 45 were under 20; 34 were female; 29 were white British; and most had low previous qualifications in comparison with others of their age (37 had low GCSE grades, the remainder had Level 2 or higher qualifications). About half received some sort of financial support, but only a minority (17) had any engagement with the labour market. Within this overall picture, there were marked differences between learner backgrounds in the North East and London. The learners in the North East were overwhelmingly white, working-class young people, whereas in London the cohort was more mixed in terms of both age and ethnic group, due mainly to the impact of recent arrivals from African countries. Many learners across the learning sites experienced multiple disadvantages. Despite such difficulties, aspirations were high; most wanted to progress to the next qualification level and nearly half talked of eventually going to university (Hodgson et al., forthcoming). However, multiple interacting disadvantages affected attendance, punctuality and behaviour in ways that made learner aspirations difficult to achieve.

Staff saw the background and behaviour of their learners as a central factor influencing TLA and their professional lives and all were well aware of the difficulties described above. Teaching learners who were 'lively, spirited and confrontational' (A1T2/4) was recognised to be 'damned hard work' (B2M3/3). Staff responded to these challenges by providing regular feedback on assignments; being prepared to meet learners in corridors for informal discussions and offering them constant encouragement. These efforts were widely recognized, and the overwhelming majority of learners interviewed were happy with their FE experience. Our sample, whose views reflected national survey findings (LSC 2006), said they enjoyed their 
courses because they felt they were learning and achieving through a more practical and vocational curriculum, reinforced by a strong social and group culture. However, this responsiveness from tutors came at a price (see Edward et al., 2007 for further discussion of professional life in the LSS). Across the four colleges, tutors talked of having to work long hours to prepare materials and to support intensive systems for monitoring learners. High degrees of learner satisfaction in FE can be achieved, but at the cost of high levels of staff stress and dissatisfaction. The Learning and Skills Development Agency (LSDA) reported that staff satisfaction rates in FE were 'worryingly low' (2005: 21), which fits the picture we found too.

\section{f. Qualifications}

These are a powerful mechanism in terms of TLA and inclusion because, particularly within this sector qualifications determine in considerable detail the content of what is to be learned, how learners achieve and how that achievement is recognized. In doing so, they provide a significant role for agencies such as QCA and the Awarding Bodies.

Senior managers, echoing wider consultations within the LSS (LSDA, 2005), thought that the qualifications system was too inflexible. They talked of the need to develop a more flexible approach to qualifications appropriate for learners in FE - providing them with bite-sized learning opportunities that they can gradually accumulate; having accreditation that recognizes the gradual process of achievement, particularly at the lower levels, and supporting flexible forms of attendance. Two of the colleges attempted to 'unitize'x their provision and one, in particular, had gone a long way down this road, running in advance of the Tomlinson proposals (Working Group on 14-19 Reform) and the Framework for Achievement (QCA, 2005). Both these colleges have had to restrict further developments in this area because of slow 
developments in national policy on credit. In the meantime, the LSC has been threatening not to fund anything that is not a whole nationally recognized qualification. Senior managers complained that this worked against college attempts to both meet the needs of their most disadvantaged learners and to engage with small and medium-sized enterprises.

\section{g. Local labour market and employer relations}

All the colleges maintained they were responsive to their local labour markets and engaged with employers, although this picture has been contested in recent government policy documents (e.g. DfES, 2006) ${ }^{\times i}$. However, college management did not believe that policy, and the ways that policy levers operated, adequately supported this. Senior managers reported that colleges needed to provide flexible learning opportunities and accreditation to meet employer needs and to have expert staff flexibly available. They also have to generate sufficient employer demand to make the supply of provision viable. They remarked, however, that it was very difficult under current policy and LSC funding and regulation to create these supply/demand conditions. Moreover, the ways that policy levers demand efficiency means that colleges have to deploy their most expert staff in areas of high learner demand. As one senior manager put it:

'You either disadvantage the groups of students by mucking up their timetable to respond to the employer over there, or you can't provide what the employer wants, so immediately becoming non-responsive' (ZA05).

There was also the issue of employer demand. Another remarked that given the reluctance of small employers to pay for training, moving away from work-based training based on public subsidy 'is going to be very difficult to engineer...and it is 
going to be over a very long period of time' (ZA06).

\section{h. Internal learning environment}

Interviewees also reported a number of 'internal' college factors, constituting what we term 'the internal learning environment' thought to be influential in relation to TLA and inclusion. These include management style and strategy; professional identity and communities of practice and college learning environments (including college monitoring systems and college approaches to TLA and inclusion), and we deal with them in turn. ${ }^{\text {iii }}$

\section{i. Management style and strategy}

Like Lumby and Tomlinson (2000), we found that both management and staff could share an educational value, for example the need to support disadvantaged learners, but disagree over how it should be realised. Management style differed because of different personalities and also because of ways in which college leaders responded to a range of factors - the constraints of the local ecology, funding and the capacities of the college workforce. Management style was also affected by the mediating role of middle managers (Leader, 2004; Briggs, 2005) and influenced how far college leaderships attempted to centralize their response to these factors. The centralization of college services and systems (e.g. learning support, quality assurance sections, specialized tutoring and cross-college monitoring arrangements) have been marked features of FE in recent years in order to ensure that these services look attractive to learners and guarantee consistency of practice.

Centralisation of college services, like other responses to policy levers, can also come at a price. If a significant proportion of senior staff are withdrawn from teaching in order to run in central services, this may leave courses more dependent on part- 
time or agency staff. This process can also be seen as part of the centralization of college policy more generally, with management style, like policy, being perceived as top-down and remote even though staff may agree with its aims. Two of the colleges, in particular, appeared to fit this pattern. District College, on the other hand, provided middle management with a significant degree of autonomy. Pragmatic devolution appeared to produce a variety of management approaches in different departments and sections. For example, one department was managed in a very interventionist way, while another emphasized a professional team-based approach.

\section{ii. Professional identity and communities of practice}

A strong theme in the interviews was the influence of professional identity, the role of course teams and the different ways these teams could be seen as operating as 'communities of practice', a term referring to the level of self-organization of professionals informed by a code of ethics and shared practice (Lave and Wenger, 1991; Wenger, 1998). Course teams have been an historical feature of full-time vocational courses (Stanton, 2004), but our evidence suggests that their role in organizing TLA and mediating the role of policy levers was based on the extent to which tutors were aware of their vocational role in preparing young people for the demands of the labour market and how this affected their relationship with management attempts to establish common monitoring systems. We detected two basic patterns across the eight learning sites. In the first, teams were formed around 'strongly vocational' courses such as nursery nursing, bringing together tutors with a shared professional background:

'We have all been nursery nurses. We know what the job entails. We know what employers are looking for and the current cohort of tutors are all working towards that assumption, that hopefully we are producing nursery nurses that are fulfilling what industry wants' (A1T1/3). 
A business studies department illustrated a different process. Business studies courses, particularly at the lower levels, attract learners not only interested in business as a vocational area, but also those looking for a more applied form of general education or those denied access to more popular courses. Business studies could, therefore, be regarded as having features of a 'default subject'. Moreover, in some instances, members of business studies' teams did not share strong business backgrounds, being involved in what has been termed 'weakly vocational' provision (Stanton, 2004). As Hodkinson et al. comment on successful students on such courses "[They] learned how to good students of business studies, not how to be business employees" (2007: 93).

In one of the colleges, the response to low retention rates and the problems of student recruitment for business studies courses prompted the appointment of a middle manager with experience of 'turning around departments'. This person proceeded to create a learner monitoring system based on the use of a prescribed set of assignments, 'criteria chasing' in relation to assignment completion and intensive monitoring of learner performance. ${ }^{\text {xiii }}$ Staff reluctant to work with the new manager's system were replaced or moved to another part of the college. The manager robustly defended this top-down strategy because of its positive effects on learner retention and, in the absence of any concerted response by tutors, was able to justify this course of action as the only solution to meeting learner needs and college targets. What we may be seeing here is the top-down creation of professional identity in the context of a weakly defined vocational area, low level of learner demand and the influence of college targets.

\section{iii. Learner monitoring systems}

The development of tight monitoring systems (focused on attendance, punctuality, 
meeting deadlines and the assessment criteria of qualifications), was an important response both to the demands of funding, targets and inspection and to the perceived needs of learners on Level 1 and 2 courses. These monitoring arrangements not only provided data, but also acted as formative feedback to those learners thought to require constant intervention, delivering what has been referred to as a system of 'overwhelming support' (Ecclestone, 2006), that risked spoon-feeding the learner and exhausting the tutor. The resulting arrangements were more or less intense or mechanical. There were complaints from tutors about the sheer tedium of intensive monitoring processes. However, this approach was not always used with regard to assessment. A variety of strategies was being employed to support teaching, learning and achievement. Some of these were influenced by the qualifications used, but a great deal of what happened was due to the ways colleges and individual learning sites organized professional practice. One senior manager made the distinction between strait-jacketing in relation to policy and funding and the 'immense amount of freedom in terms of the type of learning that goes on and how to deliver that' (ZA13).

\section{The interaction of policy levers and other national, local and institutional} factors

FE staff could see both positive and negative effects of the five policy levers on provision, on learners and on their professional lives, reflecting their complex and, at times, contradictory operations. There were also perceived tensions between and within the policy levers, particularly in the field of learner recruitment and retention (e.g. pressure for learner numbers might mean recruiting learners not well matched to particular courses). Moreover, the complexity and transaction costs of these multiple forms of intervention, while not easily measured, could be high, with the 
effect of deflecting the energies of tutors and managers from the core mission of teaching and learning.

The reporting by staff of 'other factors' influencing TLA introduces new dimensions into the analysis. We are able to see complex processes in which funding, targets and inspection interact with other national factors (for example, competence-based qualifications) and those generated by the institution. These multiple influences on learning have also been recognised in a closely related project within the Teaching and Learning Research Programme Transforming Learning Cultures in Further Education (see James and Biesta, 2007). In order to meet the 'needs' of Level 1 and Level 2 learners, colleges and learning sites felt it necessary to develop centralised and college-wide monitoring systems; these institutional systems form a particular conduit between national policy levers and TLA.

\section{CONCEPTUALISING THE IMPACT OF POLICY LEVERS ${ }^{\text {xiv }}$}

In this section, we attempt to conceptualise the processes by which policy levers impact on learning in the four FE colleges and eight learning sites. Using sources of evidence from the site visits, related to wider literatures on further education, management and governance, we tentatively develop three related concepts 'processes of mediation', 'acts of translation' and 'local ecologies' - in order to help understand ways in which these FE colleges and learning sites responded to national policy levers and the demands of their local environment. ${ }^{\mathrm{xv}}$

\section{Processes of mediation and acts of translation}

As explained earlier in the paper, we have found it useful to adapt and develop two 
related concepts - processes of mediation and acts of translation - to help understand how policy and more specifically, national policy levers, impact on learning in a multi-level LSS.

We use the term mediation in two related senses. First, seen from the perspective of education professionals, we use it to describe a general and continuing 'process' (James and Biesta, 2007) by which different actors within the LSS respond to and act upon policy. We do not ascribe to 'mediation' a particular quality of action, for example, "to adapt particular reforms to make them work" (Wallace and Hoyle, 2005:12), but like James et al. (2007), we see mediation as an interactive process, giving rise to a spectrum of responses or 'interventions'. It is within this more general definition that we discuss particular 'acts of translation' that link policy levers to learning. Second, seen from the perspective of national systems, policy-making and policy trajectories, we use the term 'policy mediation' to help understand the changes that policy itself goes through as it moves down the system and through stages of the policy process. This is seen as a set of interactions as policy levers come into contact with existing systems, structures and cultures, the professional capacity and values of staff, pressures from the local environment, and successive translations of policy at different levels. We link 'policy mediation' to arguments about the dysfunctional effects of policy levers in their long journey down the LSS from policy-makers to practice.

Acts of translation should not be seen as a single event but as a complex process of interpretation and re-interpretation at different levels within the LSS. So, for example, we use 'acts of translation' as a term to describe how FE managers and tutors interpret both pressures from national policy levers and from their local environment and then convert these into internal strategies, roles, systems and practices. The term also allows for a spectrum of constraint and agency, ranging from narrow or 
'constrained' acts of translation under pressure from policy levers, to more 'open' ones, where institutional leaders have the 'space' to balance demands from the national and local levels as they seek to make policy both manageable and understandable to themselves and their staff. The spectrum of acts of translation is closely allied to Shain and Gleeson's notions of 'compliance' and 'strategic compliance' (1999).

\section{Policy levers, the 'chain' and unintended outcomes}

Evidence from our learning sites and from project engagement events (see Edward and Coffield, (2007) for an explanation of the Project's engagement strategy), suggests that the effects of multiple acts of translation and re-translation of policy at different points in a long 'chain' within the LSS and within the institution (e.g. DfES -National LSC -- Regional LSC -- Local LSC -- senior college management -- middle college management -- tutors), can sometimes produce what policy-makers see as the 'misreading' of policy, leading to 'unintended outcomes' (see Steer et al., 2007), for example, the generation of high transactions costs ${ }^{\text {xi }}$.

Such unintended outcomes may be the result of conflicting processes at different levels of the LSS. On the one hand, there are increasing attempts by government to tighten control over 'the chain' through LSC reorganization, particularly at the regional level, reducing the number of targets and focusing on funding priorities. On the other, different actors within the LSS, who have been excluded from shaping policy and its mechanisms, enter at the 'practice' stage of the policy cycle (Bowe et al., 1992). At this point, they affect the trajectory of policy as they consider, through the lens of their educational values and understanding, not only policy levers but also other pressures from the locality or from sources within the national system. The combined effects of the policy levers As Section 3 of the article illustrates, national policy levers did not act in isolation but 
worked together. Combination can be seen as a way of increasing the power of policy levers and, on the surface at least, this appeared to be the case. Targets and funding were powerful because they affected institutional economic viability and brought the college into an accountability relationship with the LSC. However, they did not necessarily produce desired outcomes, stability or responsiveness. The constant shifting of priorities and of funding through the annual grant letter to the LSC, and the knock-on effect to institutions were seen by some as threatening the ability of colleges to plan ahead and to improve their professional capacity. Moreover, policy levers operating in combination appeared to lessen the scope for a proactive relationship with the needs of the locality; increased the incidence of perverse forms of compliance (for example, institutional threats to cut ESOL provision even though this was not intended in national policy) and encouraged various forms of 'gaming' behaviours, a point echoed by LSDA (2005) in its research on the sector as a whole. $^{\text {xvii }}$

The combined effects of policy levers also contributed to mounting 'transaction costs'. These refer to the time, energy and resources devoted to contracting and accountability systems. These costs are replicated at different levels within colleges, including - the constant redrafting of plans by senior management; delivering data to the LSC and other national agencies; the absorption of the time of middle managers as these demands are translated into college systems and the time of tutors as they respond to the demands of college systems. While the DfES and the LSC have repeatedly emphasized the need to cut back bureaucracy ${ }^{x v i i i}$, we found no evidence of significantly diminished procedures in our learning sites.

Mediation, management style and professionalism

The process of mediation and acts of translation were affected by the professional or 
political values of managers and tutors. The outcome was a complex mix of institutional self-interest; ethical behaviour; conflict and agreement, reflecting subtle relations identified by previous research on FE (e.g. Randle and Brady, 1997; Shain and Gleeson, 1999; Lumby and Tomlinson, 2000; Bathmaker 2005).

The nature of agreement and disagreement within FE colleges in the learning and skills era appears to be more complex than the disputes between managers and professionals that characterized the early days of Incorporation highlighted, for example, by Randle and Bradey (1997). Our evidence does not point to an end of teacher and manager conflict in FE but the addition of further layers of tension, notably colleges versus the LSC and the regulatory system and the ways in which these tensions are played out internally. Points of disagreement between tutors and managers were not so much based on the right to manage and the preservation of professional conditions of service, but on the effects of constant reorganization and how to meet learner needs while meeting the demands of targets. There were, however, high levels of agreement between managers and tutors on the need for inclusive systems and practices (e.g. generating the many inclusion practices that arose both formally and informally within the colleges), a point highlighted by others (e.g. Lumby and Tomlinson, 2000), but this agreement could break down around the bureaucracy and data collection associated with college-wide systems of monitoring achievement.

We also found examples what of can be termed 'shielding', 'policy lever reduction' and 'ethical gaming', where senior, and sometimes, middle management would take the brunt of the effects of funding rather than passing them onto tutors, or reduce paperwork in response to tutor feedback or shield learners from the effects of funding turbulence (e.g. by creating long induction periods at the beginning of the academic year, while staff and accommodation difficulties were still being sorted). There were 
also instances of 'ethical gaming' (Dixit, 2002), in which managers and tutors in some of the learning sites would play the system or bend rules to ensure the courses could continue to function in the interest of learners. This mediating function of middle managers highlights their growing strategic role in FE colleges (Leader, 2004; Briggs, 2005).

Tutors also brought their own educational values into the equation. The degree to which this happened in the learning sites appeared to be linked to the degree of vocationalism and vocational ethos in course teams. Vocational and professional identity was reinforced by the clear demands of the labour market on vocational courses and, in particular, by 'license to practise' and 'professional standards' demands in certain courses such as Care and Construction.

The interaction of policy levers and 'other factors' in the mediation process As Section 3 demonstrates, policy levers interacted with other factors within the colleges and learning sites to affect TLA and inclusion. These included professional assessment of learner needs; the kind of qualifications taken and their demands; management style at both senior and middle levels; college monitoring systems and the nature of the professional organization of tutors. This complex interaction, giving rise to what we have termed the process of 'policy mediation', could not have been anticipated by national policy-makers.

Overall, it is possible to identify two trends in these mediation processes. The first could be described as reproduction, in which management in the colleges translated policy instruments in such a way that the dysfunctions of the LSS were recreated within the institution (e.g. the policy instruments became the aims of the institution; continual reorganisation; multiple data-gathering and bureaucracy, remote management style and intervention in professional practice). The second could be 
viewed as taking ownership (e.g. both management and teaching staff held strong professional values about learners and the purposes of education and brought these the mediation process by fostering strong internal 'communities of practice' focused on improving the outcomes for learners and, in particular, protecting the wider interests of the most disadvantaged). The ways in which policy was mediated within the four colleges and the eight learning sites lay, at varying points, between the two poles of reproduction and taking ownership.

\section{Local ecologies}

The concepts of 'ecologies' or 'eco-systems' have mainly been used to refer to dynamic interactions between plants, animals, and micro-organisms and their environments working together as a functional unit. In recent years, however, these terms have inspired theorists in different fields to use them as a metaphor, and as a holistic form of system thinking in order to appreciate multiple, complex and interdependent relations and processes in different 'spaces' or levels of systems or societies (e.g. Bronfenbrenner, 1979; Finegold, 1999; Stronach et al., 2002). The concept of ecologies can also be related to Bourdieu's concept of 'field', which focuses on "the state of the relations of force between players that define the structure of the field" (Bourdieu and Wacquart, 1992: 99). Field has to be understood on different levels or scales, from the individual to the global (see James and Biesta, 2007 for an application of the concept of 'field' to FE).

Here we use the metaphor of 'local ecologies' to refer to the inter-dependent relationships of different providers in a locality in which the behaviour of one provider can affect the success or failure of others' (Stanton and Fletcher, 2006: 15). We have expanded Stanton and Fletcher's concept, used to examine 14-19 institutional arrangements, to embrace a wide range of local factors which colleges must consider 
when attempting to function effectively within their locality. These include different local competitive or planning environments; configurations of institutional provision; local labour markets and patterns of skills levels and employer demand; local demography and geography, social conditions, the needs of learners and their patterns of travel to college. ${ }^{\text {ix }}$

Ecologies are, therefore, about relationships in different contexts and spaces that differ in size and overlap. The ecological landscape of an FE college is complex and differentiated because it comprises both meso and micro ecologies - a whole region, if the college offers a highly regarded vocational specialism; a sub-region, in terms of labour markets or lifelong learning partnerships and numerous outreach community based centres for adult learning. The complexity of the FE college ecology makes these institutions highly vulnerable to constant shifts in different areas of policy and to mounting transactions costs from multiple accountability systems.

The concept of local ecologies does not signal a particular quality of relationships, even though the metaphor encourages thinking about inter-dependence. The 'condition' of local ecologies will necessarily vary. Relations can be more competitive or collaborative, rich or impoverished, strained or harmonious. For example, colleges currently function within largely competitive local ecologies in which they are expected to perform a reactive role to schools (e.g. taking low achieving and disaffected learners that many $11-18$ schools and sixth form colleges do not cater for) and a proactive role in relation to vocational and work-based learning, literacy and adult learning and the expansion of higher education. As yet, it is not clear from our data, however, whether the colleges in our sample want greater freedom and stability to compete more effectively, or to collaborate with other providers, or to become involved in some new mixture of the two, where they combine with other potential rivals to win larger contracts which no one institution could attract on its own. 
Several senior college managers in our sites suggested that that some national policy levers (e.g. funding and targets) were impairing the ability of their institutions to work effectively with local ecologies, particularly in relations to adults, and that the policy of contestability and the brokering role of the LSC in Train to Gain was disrupting established college/employer relationships.

The concept of local ecologies may be useful, therefore, relationships between local and national levels and between local partners under current policy conditions. The concept might also be used to suggest how national policy and governance arrangements in the LSS might be changed in order to help providers improve the condition of the local ecology itself and the quality and inclusiveness of the local educational landscape.

Our research in these colleges and learning sites suggests that the cumulative effects of acts of translation within the LSS and the complex processes of policy mediation within the FE colleges and sites of learning produced both unpredictable outcomes and high costs. We conclude by suggesting that the Sector might become a better functioning ecological system if policy levers, that play a powerful role in mediation processes, are shaped more at the local level where their complex interactions are better understood.

\section{REFERENCES}


Bourdieu, P. and Wacquat L.J.D. (1992) An Invitation to Reflexive Sociology (Cambridge, Polity Press).

Bronfenbrenner, U. (1979) The ecology of human development: Experiments by nature and design (Cambridge, Ma., Harvard University Press).

Bathmaker, A-M. (2006) 'Alternative futures: professional identity formation in English Further Education' in Satterthwaite, J., Martin, W. and Roberts, L. (eds) Discourse, Resistance and Identity Formation (Stoke on Trent, Trentham Books).

Bowe, R., Ball, S. J. and Gold, A. (1992) Reforming Education and Changing Schools: case-studies in policy sociology (London, Routledge).

Briggs, A. (2005) Middle managers in English further education colleges: understanding and modelling the role, Education Management, Administration and Leadership Vol. 33, No. 1, 27-50.

Coffield, F., Steer, R., Hodgson, A., Spours, K., Edward, S. and Finlay, I. (2005) A new learning and skills landscape? The central role of the Learning and Skills Council, Journal of Education Policy, 20 (5) 631-656.

Coffield, F. and Edward, S. (forthcoming) Rolling out 'good', 'best' and 'excellent' practice. What next? Perfect practice?, British Journal of Educational Research Department for Education and Skills (DfES) (2002) Success for All: Reforming further education and training: our vision for the future (London, DfES).

-- (2003) Trust in the Future: Report of the Bureaucracy Task Force (London, DfES).

-- (2006) Further Education: Raising Skills, Improving Life Chances (Norwich, Stationery Office).

Dixit, A. (2002) Incentives and Organizations in the Public Sector: An Interpretative Review, Journal of Human Resources 37, 696-727.

Ecclestone, K. (2006) Learner autonomy in FE. Paper presented to BERA conference 2006, University of Nottingham

Edward, S. and Coffield, F. (2007) Policy and practice in the learning and skills sector: setting the scene, Journal of Vocational Education and Training, 59(2) XXX$\mathrm{XXX}$

Edward, S., Coffield, F., Steer, R. and Gregson, M. (2007) Endless change in the learning and skills sector: the impact on teaching staff, Journal of Vocational Education and Training, 59(2) XXX-XXX 
Finegold, D. (1999) Creating self-sustaining, high-skill ecosystems Oxford Review of Economic Policy 15 (1) 60-81.

Hodgson, A., Spours, K., Coffield, F., Steer, R., Finlay. I., Edward, S. and Gregson, M. (2005) A New Learning and Skills Landscape? The LSC within the learning and skills sector, Research Report 1. (London, LEID, Institute of Education, University of London).

Hodgson, A., Steer, R., Spours, K., Edward, S., Coffield, F., Finlay, I. and Gregson, M. (2007) Learners in the English learning and skills sector: The implications of halfright policy assumptions, Oxford Review of Education, 33 (3) in press.

Hodkinson, P., Biesta, G. Postlethwaite, K. and Maull, W. (2007) 'Learning cultures across sites' in James, D. and Biesta, G. (eds) Improving Learning Cultures in Further Education (London, Routledge).

James, D. and Biesta, G (2007) (eds) Improving Learning Cultures in Further Education (London, Routledge).

Lave, J. and Wenger, E. (1991) Situated Learning (Cambridge, Cambridge University Press).

Leader, G. (2004) Further Education Middle Managers: Their contribution to the strategic decision-making process, Education, Management, Administration and Leadership 32, (1) 67-79.

Learning and Skills Council (LSC) (2003) Success for All: Implementation of the Framework for Quality and Success, Circular 03/09 (Coventry, LSC).

-- (2004) Agenda for Change (Coventry, LSC).

-- (2006) National Learner Satisfaction Survey: Highlights from 2004/5 (Coventry, LSC).

Learning and Skills Development Agency (LSDA) (2005) The Review of the future role of FE colleges (London, LSDA).

Lumby, J. and Foskett, N. (2005) 14-19 Education: policy, leadership and learning. (London, Sage).

Lumby, J. and Tomlinson, H. (2000) Principles speaking: managerialism and leadership in further education, Research in Post-Compulsory education. 5 (2) 139152.

Martinez, P. and Munday, F. (1998) 9000 voices: student persistence and drop-out in FE. FEDA Report, Vol 2, No 7. 
Perry, A. and Simpson, M. (2006) Delivering quality and choice: how performance indicators help and how performance indicators hinder (London, LSDA).

Qualifications and Curriculum Authority (QCA) (2005) Framework for Achievement (London, QCA).

Randle, K. and Brady, N. (1997) Managerialism and Professionalism in the 'Cinderella Service, Journal of Vocational Education and Training 49 (1) 121-139.

Shain, F. and Gleeson, G. (1999) Under new management: changing perceptions of teacher professionalism and policy in the further education sector, Journal of Education Policy 14 (4) 445-462.

Stanton, G. (2004) The organisation of full-time 14-19 provision in the state sector. Nuffield 14-19 Review Working Paper 13 at www.nuffield1419review.org.uk/documents.shtml, accessed September 2006

Stanton, G. and Fletcher, M. (2006) 14-19 Institutional Arrangements in England - A research perspective on collaboration, competition and patterns of post-16 provision. Paper prepared for Nuffield Review of 14-19 Education and Training Seminar, 12 July 2006.

Steer, R., Spours, K., Hodgson, A., Finlay, I. Coffield, F., Edward, S. and Gregson, M. (2007) 'Modernisation' and the role of policy levers in the Learning and Skills Sector, Journal of Vocational Education and Training, 59 (2) XXX-XXX

Stronach, I., Corbin, B., McNamara, O., Stark, S. and Warne, T. (2002) Towards an uncertain politics of professionalism: teacher and nurse identities in flux, Journal of Education Policy 17 (1) 109-138.

Wallace, M. and Hoyle, E. (2005) Towards Effective Management of a Reformed Teaching Profession paper presented to the ESRC TLRP thematic series 'Changing Teacher Roles, Identities and Professionalism, Kings College, London, 5 July.

Wenger, E. (1998) Communities of Practice: learning, meaning, and identity (Cambridge, Cambridge University Press).

Working Group on 14-19 Reform (2004) 14-19 Curriculum and Qualifications Reform: Final report of the Working Group. (London, DfES).

\section{Notes}


${ }^{\mathrm{i}}$ The researchers wish to acknowledge the funding of this Teaching and Learning Research Programme project by the Economic and Social Research council - reference number RES139-25-0105.

ii The LSS refers to the Learning and Skills Sector in England, formed in 2001, that comprises 16-19 education and training, adult learning and work-based learning but not higher education.

iii The FEFC (Further Education Funding Council), formed in 1993, was responsible for the funding of a national further education sector. It was absorbed into the Learning and Skills Council (LSC) in 2001.

${ }^{\text {iv }}$ Each interviewee has been given a code which indicates the learning site, professional role and the number of the visit.

${ }^{v}$ This paper draws on only a part of our total data from the eight FE learning sites. Additional project outputs will report other aspects of the data.

${ }^{\mathrm{vi}}$ All our institutions have been given pseudonyms.

vii In this paper, by term 'learning', we are referring to teaching, learning and assessment (TLA).

viii Ofsted (Office for Standards in Education) is the education inspectorate in England.

ix EMAs (Education Maintenance Allowances) are a financial inducement paid to certain 16-19 year olds to encourage them to participate in post-16 education and training.

x The term 'unitize' refers, in this case, to college strategies aimed at developing a comprehensive and flexible offer by using qualifications which are made up of units e.g. Open College Network (OCN) and breaking other qualifications, such as BTEC diplomas, into units of assessment to be delivered across a range of Level 1 and 2 provision.

${ }^{x i}$ The White Paper on FE claimed that " $82 \%$ of employers did not use colleges at all" and that "7\% of employers who used FE colleges during the last year were 'not very' or not at all' satisfied with provision (DfES, 2006: 15).

xii We have not reported in this paper staff responses on factors affecting the development of 'good practice', which is a focus of another project publication. See Coffield and Edward (forthcoming).

xiii The term 'criteria chasing' refers to the practice of monitoring learners' completion of a piece of work by focusing attention on each and every assessment statement. This can involve the drafting and redrafting of work as the learner inserts material to meet multiple assessment criteria.

${ }^{x i v}$ A discussion of the concept of policy levers can be found in Steer et al. 2007 (this volume).

xv The ideas discussed in this section and any conclusions drawn are tentative. We intend to discuss these further in consultation with researchers, practitioners and policy-makers in the LSS.

xvi The theme of 'translation problems in the LSS' was explored in a seminar held in November 2006 in York involving policy-makers from the DfES, National and Region LSC, practitioners from the Project Learning sites and researchers from the Institute of Education.

xvii Gaming, in the context of post-compulsory education, is a term used to describe ways in which accountability systems and incentives are used to gain institutional advantage by playing the system or bending the rules (Lumby and Foskett 2005).

xviii Measures include Success for All (DfES 2002), the work of the Anti-Bureaucracy Taskforce (DfES 2003), under Sir George Sweeney and the new LSC Business Model under Agenda for Change (LSC 2004).

xix The metaphor of local ecologies will be developed in future project outputs. 